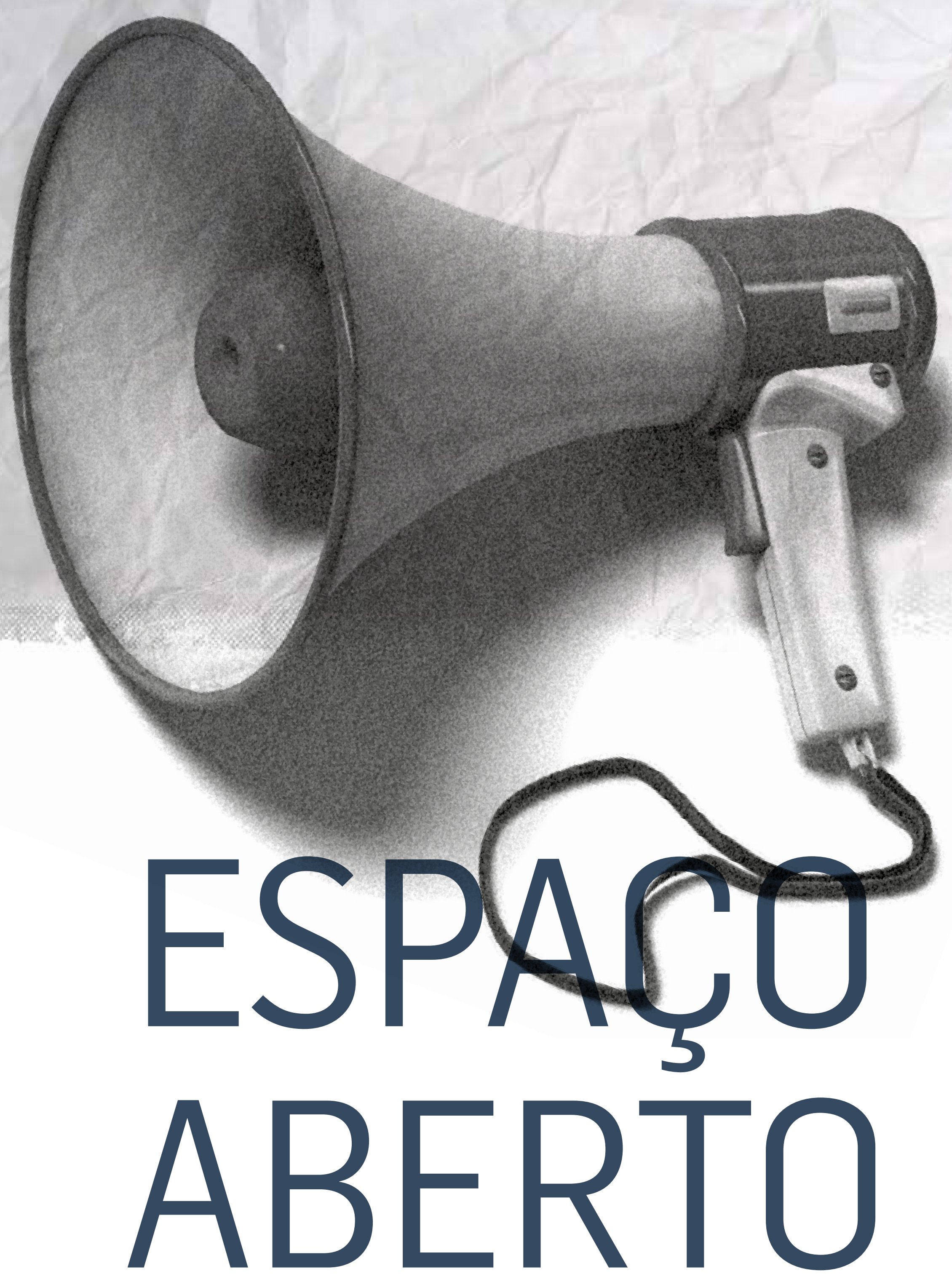




\title{
Marcas organizacionais e o patrocínio de causas sociais alternativas: 0 daltonismo
}

\author{
Organizational trademarks and the sponsorship \\ of alternative social causes: daltonism
}

\section{Marcas organizacionales y el patrocinio de causas sociales alternativas: el daltonismo}

\section{Kleber Markus}

- Pós-doutor pela Université René Descartes (Paris V - Sorbonne)

- Doutor e mestre em Ciências da Comunicação pela Escola de Comunicações e Artes da Universidade de São Paulo (ECA-USP)

- Curso de extensão em Novas Tecnologias da Comunicação pela University of Florida

- Professor em cursos de graduação e no Programa de Pós-Graduação em Comunicação da Universidade Metodista de São Paulo (Póscom-Umesp)

- Docente dos cursos de pós-graduação lato sensu de Gestão Estratégica em Comunicação Organizacional e Relações Públicas e Gestão de Comunicação e Marketing, da ECA-USP

- Coordenador assistente do Centro de Estudos de Avaliação e Mensuração em Comunicação e Marketing (Ceacom) da ECA-USP

- Coautor do livro Marketing fácil (Saraiva, 2012)

- E.mail:kmarkus@uol.com.br

Gustavo Henrique Del Vechio

- Mestre em Comunicação Social pela Universidade Metodista de São Paulo (Umesp)

- Doutorando em Comunicação Social na Umesp

- Graduado em Comunicação Social, com ênfase em Publicidade e Propaganda, pela Faculdade de Educação São Luis (FESL), de Jaboticabal (SP)

- Docente da Faculdade de Tecnologia (Fatec) de Bebedouro (SP)

- Autor dos livros Illustrator CS4: o design em suas mãos(Érica, 2010) e Design gráfico com Adobe Illustrator(Campus-Elsevier, 2012)

- E.mail: gustavodelvechio@gmail.com 


\section{Resumo}

Em um mercado com alta competitividade e saturação, valores de marcas podem ter papel decisivo na diferenciação e decisão de compra por parte dos consumidores. Essa pesquisa analisa a importância do investimento em causas sociais, não como obrigação ou autopromoção, mas como abordagem que deve se tornar premissa básica e parte da cultura das organizações. 0 recorte da pesquisa volta-se ao estudo de causas sociais menos difundidas ou de menor repercussão midiática, procurando verificar se o investimento nelas pode se refletir em valores para marcas, assim como se espera do apoio a causas mais conhecidas, como o câncer, a pobreza ou a fome. 0 estudo se complementa a partir de entrevistas em profundidade com executivos do Grupo Abril e da Volkswagen do Brasil, para avaliar como essas organizações se posicionam frente à possibilidade de investir em causas menos conhecidas, por exemplo o daltonismo.

\section{PALAVRAS-CHAVE: RESPONSABILIDADE SOCIAL・MARCAS・PATROCÍNIO • COMUNICACÃ̃O・DALTONISMO.}

\section{Abstract}

In a market with a high level of competiveness and saturation the values of trademarks can have a decisive role in the differentiation and in the purchasing decisions of consumers. This research analyzes the importance of investment in social causes, not as an obligation of self-promotion, but rather as an approach that must become a basic premise and a part of the culture of the organizations. The clipping of the research addresses the study of less diffused social causes, or of those that have less mediatic repercussion, seeking to verify if the investment in them can be reflected in value for the trademarks, such as one expects of the support of better-known causes, such as cancer, poverty or hunger. The study is supplemented by profound interviews held with executives of the Abril Group and of Volkswagen do Brasil, in order to assess how the organizations position themselves in relation to the possibility of investing in less-known causes, such as daltonism for example.

\section{KEYWORDS: SOCIAL RESPONSIBILITY・TRADEMARKS •SPONSORSHIP・COMMUNICATION・DALTONISM.}

\section{Resumen}

En un mercado de alta competitividad y saturación, valores de marcas pueden tener un papel decisivo en la diferenciación y decisión de compra de parte de los consumidores. Esta investigación analiza la importancia de la inversión en causas sociales, no como obligación o autopromoción, sino como abordaje que debe tornarse premisa básica y parte de la cultura de las organizaciones. El recorte de la investigación se dirige al estudio de causas sociales menos difundidas o de menor repercusión mediática, procurando verificar sila inversión en ellas puede reflejarse en valores para marcas, asícomo seespera el apoyo a causas más conocidas, como el cáncer, la pobreza o el hambre. El estudio se complementa a partir de entrevistas en profundidad con ejecutivos del Grupo Abril y de la Volkswagen del Brasil, para evaluar cómo esas organizaciones se posicionan frente a la posibilidad de investir en causas menos conocidas, por ejemplo el daltonismo. 
uando as organizações investem em causas sociais, elas ajudam entidades, reforçam seu compromisso com a sociedade, melhoram sua imagem pública e agregam mais credibilidade às suas marcas. Essa constatação está alicerçada em estudos de vários pesquisadores de gestão de marcas, comunicação, marketing ou relações públicas, como Baldissera, Calkins, Keller, Kotler, Semprini, Tybout e Yanaze, cujas obras que se referem ao assunto são citadas no decorrer da pesquisa.

0 objeto da pesquisa não é, entretanto, qualquer tipo de causa social, mas sim um estudo sobre o estágio no uso de causas sociais menos difundidas, que poderiam ser apoiadas por marcas organizacionais com influência no mercado brasileiro, mas que se concentram em um número reduzido de grupos sociais ou em uma região específica do país. Um exemplo de causa social dessa natureza, escolhido para avaliação dentro da pesquisa, é o daltonismo, que parece receber pouca atenção de marcas interessadas em investimentos sociais, nem mesmo aquelas em que a cor é um elemento principal em seu core business. Logo, o que se pretende refletir é como grandes marcas organizacionais se posicionam frente ao investimento em ações sociais mais pontuais, em vez de se voltarem inexoravelmente para causas de grande abrangência midiática ou temas mais conhecidos na sociedade.

O objetivo geral da pesquisa é analisar se essas causas alternativas também podem gerar retorno e ajudar no posicionamento das marcas, assim como se espera da exploração de temas como o câncer, a educação e o apoio ao esporte, que muitas vezes nem estão ligados diretamente ao negócio principal das organizações. Para dar suporte a esse objetivo geral, a pesquisa primeiro realiza uma análise da trajetória do marketing nas últimas décadas, depois avalia o papel das marcas na sociedade contemporânea e como o investimento em causas sociais pode ser uma boa alternativa para organizações que desejam se diferenciar. Não há a expectativa, neste estudo, de avaliar uma quebra de paradigma, mas sim de compreender de que forma os executivos de comunicação ou marketing de organizações conceituadas se posicionam frente à proposta de investir em causas sociais menos difundidas ou de menor repercussão midiática.

\section{TRAJETÓRIA DO MARKETING}

No livro Marketing 3.0, os autores, Philip Kotler, Hermawan Kartajaya e Iwan Setiawan (2010, p. 29) iniciam o primeiro capítulo afirmando que "ao longo dos anos, o marketing evoluiu". Ao seguir a leitura pelos capítulos da obra, nota-se que tal evolução não se deve a acontecimentos ao acaso e nem se trata de um conjunto de eventos desencadeados apenas nos últimos anos; o que esses autores evidenciam é que o marketing vem se alterado constantemente ao longo da história humana, sobretudo nas seis últimas décadas, isto é, a partir de 1950.

Alvin Toffler (2014, p. 28) lembra que, por volta de 1950, os profissionais em cargos administrativos, burocráticos e de serviços gerais excederam em números os trabalhadores que exerciam atividades braçais, sendo aquela década também marcada pela introdução do computador, do jato comercial, da pílula anticoncepcional e de muitas outras invenções de alto impacto. Para esse autor, tais tendências deram origem à chamada "terceira onda" de mudança social, política, econômica e cultural'.

Mitsuru Yanaze (2011, p. 31-32) complementa que após a Segunda Guerra Mundial, já em um cenário de consumidores mais exigentes, as empresas começaram a se preocupar em conhecê-los melhor, investigando mais profundamente seus comportamentos e suas motivações de compra. Como reflexo, no início da década de 1950, algumas disciplinas de pesquisa

1 Para Toffler (2014), a "primeira onda" de mudanças ocorreu com a Revolução Agrícola, enquanto a "segunda onda" teve sua gênese com a Revolução Industrial. 
e análise de clientes passaram a integrar cursos de negócios em universidades dos Estados Unidos, sendo chamadas de Market studies, expressão que em pouco tempo foi substituída por Marketing².

Como se verifica, a década de 1950 representou a expansão da tecnologia e de novos meios de comunicação que se integraram a consumidores com mais potencial de compra, num ambiente com empresas cada vez mais preocupadas em entendê-los e satisfazê-los, além de se diferenciarem da concorrência. A informação passou a ser muito mais importante para empresas e consumidores, sendo que os computadores nas décadas seguintes (a partir dos anos 1990, com o advento da internet) se tornaram um valioso disseminador de informação nas sociedades ou entre elas.

Para Massimo Di Felice (2008, p. 22-23), a implementação das tecnologias digitais no cotidiano social é uma revolução comunicacional, pois o processo e 0 ato de comunicar se transformaram e permitiram, pela primeira vez na história da humanidade, um fluxo em que emissor e receptor se confundem. A comunicação para um grande número de pessoas deixou de ser reservada apenas aos meios de comunicação de massa e, em vez de se pensar em uma estrutura de via única, na qual o meio comunica e o público absorve sem muita participação, a tecnologia permitiu que qualquer pessoa pudesse ser ouvinte e ao mesmo tempo provedora de informações.

Essas mudanças, primeiro com a sociedade industrial e o surgimento da produção em massa, depois com a expansão da tecnologia e a informação muito mais acessível, resultaram em um impacto direto nas definições dos negócios. Vale resgatar que, nas sociedades industriais, o processo de fabricação de um bem de consumo estava, pelo menos em grande parte, centrado regionalmente e os laços entre fornecedores e fabricantes não se estabeleciam em escala nacional ou mundial com tamanha facilidade; novos produtos, portanto, tinham maior tempo de exclusividade perante concorrentes:

Se uma empresa tinha uma ideia interessante em 1950, demorava até outras a adotarem ou até a descobrirem. As empresas arquetípicas do início e de meados do século XX eram empresas como a mineradora sul-africana De Beers ea gigantesca americana Xerox. Estas, muitas vezes, tinham até 20 ou mesmo 30 anos para explorar globalmente vantagens de seus ativos específicos aquilo que as tornou únicas (Nordstrom; Ridderstrale, 2001, p. 24).

Nesse ambiente, o marketing podia concentrar seus esforços no produto, isto é, em melhores formas de produção, logística e divulgação. A centralização das estratégias de marketing no produto é observada desde que a publicidade começou a se popularizar e até por volta de 1950, tempo em que a produção em larga escala fabricava produtos a todo vapor. Kotler, Kartajaya e Setiawan (2010, p. 3-4) entendem essa era como a primeira fase do marketing (que eles chamam de "marketing 1.0"), cujo objetivo era padronizar e ganhar em escala, a fim de reduzir os custos de produção, para que as mercadorias pudessem ter preço muito baixo e ser adquiridas por mais compradores.

No entanto, esses tempos se passaram e a tecnologia permitiu à informação se espalhar instantaneamente e internacionalmente. Os clientes tornaram-se mais informados e a concorrência cresceu não apenas na mesma região. A competitividade atingiu nível mundial. Kotler, Kartajaya e Setiawan (2010, p. 30) afirmam que, "ao longo das décadas, os consumidores se tornaram compradores mais inteligentes".

Não seria difícil imaginar que, diante desse cenário, os planos de mercado voltados exclusivamente ao produto já não poderiam mais se sustentar. Na opinião de Kotler, Kartajaya e Setiawan (2010, p. 30), entre as décadas de 1970 e 1980, 0 marketing progrediu para uma perspectiva voltada ao cliente e seus valores, no intuito de conquistar o seu coração (essa foi a época do "marketing 2.0"). Em seguida, entre as décadas de 1990 e 2000, a tecnologia possibilitou ao marketing evoluir

2 A década de 1950, portanto, marcou o início dos estudos científicos de marketing. 
novamente para o "marketing 3.0", em que as estratégias de mercado passaram a considerar os humanos como seres plenos, isto é, dotados de mente, coração e espírito:

Os conceitos de marketing evoluíram do foco na gestão de produtos nas décadas de 1950 e 1960 para o foco de gestão de clientes nas décadas de 1970 e 1980. Em seguida evoluíram ainda mais e acrescentaram a disciplina de gestão da marca nas décadas de 1990 e 2000 (Kotler; Kartajaya; Setiawan, 2010, p. 29).

0 que se verifica é que, desde 1950, o marketing teve que evoluir para se sustentar em um novo ambiente de negócios, sobretudo com o advento da internet na década de 1990 e da popularização da banda larga e das mídias sociais após os anos 2000. Tentar atingir o coração de um indivíduo apenas agregando novas propriedades tangíveis ou melhoramentos tecnológicos já não mais funcionaria. Para Kotler, Kartajaya e Setiawan (2010, p. 34), o "marketing 1.0" e o "marketing 2.0" ainda têm certa relevância, pois se faz essencial escolher o segmento-alvo, definir o posicionamento, oferecer os 4 Ps e construir a marca em torno do produto; no entanto, as mudanças no ambiente de negócios, como recessão, preocupações com o meio ambiente, novas mídias sociais, empowerment do consumidor, nova onda de tecnologia e globalização continuarão provocando mudanças maciças nas práticas de marketing:

As empresas que praticam o marketing 3.0 oferecem respostas e esperança às pessoas que enfrentam (...) problemas e, assim, tocam os consumidores em um nível superior. No marketing 3.0, as empresas se diferenciam por seus valores. Em épocas de turbulência, trata-se definitivamente de um diferencial e tanto.

Hoje, com a informação muito mais acessível, agredir o meio ambiente, desmatar florestas, poluir rios e extrair da natureza material para produção sem devolver a ela tais subsídios, são práticas condenáveis a qualquer empresa; quando os consumidores analisam uma marca, eles também consideram as responsabilidades socioambientais dela. Organizações com valores falsos correm o sério risco de perder a credibilidade na mente dos consumidores, que facilmente compartilham suas opiniões e experiências negativas. A responsabilidade social é, portanto, um importante passo para as empresas que desejam ter uma imagem positiva na sociedade atual.

\section{MARCAS NA SOCIEDADE CONTEMPORÂNEA}

Para alguns, marca é apenas uma fonte conhecida que oferece produtos e serviços ao mercado; outros entendem uma marca como uma promessa da empresa aos consumidores sobre os benefícios de cada produto, ou até o valor que a marca oferece com relação ao seu custo. Bobby J. Calder (2006, p. 28) diz que, fundamentalmente, uma marca é um conceito; já Tim Calkins (2006, p. 1) complementa que "a marca transcende o produto", concordando que "uma marca é um conjunto de associações vinculadas a um nome, sinal, ou símbolo", como, por exemplo, a marca Dom Perignon, que traz à mente comemorações, luxo, champanhe, França e algo caro.

Como explicam Philip Kotler e Kevin Keller (2012, p.258), as diferenças entre produtos podem ser funcionais, racionais e tangíveis, bem como simbólicas, emocionais ou intangíveis. Por exemplo, um relógio da Rolex tem um valor agregado muito maior em relação a um Casio, mesmo se o material usado na composição de ambos fosse idêntico.

Para Andrea Semprini (2010, p. 53-93), o espaço social das marcas contemporâneas é uma combinação dos campos do consumo, da comunicação e da economia. 0 consumo, por muito tempo, fez seu papel de acesso ao bem-estar econômico para grande parte da população, sendo que em uma fase posterior, ajudou a afirmar o statuse a posição social dos indivíduos. 
Não significa que tais propósitos desapareceram; no entanto, as lógicas de consumo parecem agora vinculadas a aspectos da cultura pós-moderna, como o individualismo, o culto ao corpo, a imaterialidade, o imaginário e a mobilidade.

A dimensão da comunicação também é intrínseca às marcas, pois a própria publicidade surgiu tão logo elas nasceram. Para Semprini (2010, p. 72-73), hoje a marca parece acreditar que pode se libertar do produto e se transformar em um ser puro de comunicação, um criador de valor que, graças a uma comunicação bem concebida, pode agregar valor a qualquer produto ou serviço.

Enquanto a ligação entre marcas, consumo e comunicação é relativamente clara, a relação entre marcas e a dimensão econômica é menos estudada, inclusive por economistas. Semprini (2010, p. 78) argumenta que os economistas "adoram discutir em profundidade os indicadores macroeconômicos, mas evocam raramente as marcas, como se elas não desempenhassem nenhum papel no andamento econômico". Deve-se notar, todavia, que a reputação de uma organização com imagem ruim se reflete diretamente no apoio por parte dos seus investidores. Crises econômicas e de macroambiente - uma queda na bolsa de valores, aumento de impostos ou de taxas de câmbio - podem afetar diretamente os negócios das marcas organizacionais e vice-versa. Com a globalização de mercado, isso se torna ainda mais agravante, pois as crises em um polo podem afetar investidores e se propagar para muitos países.

Não há um método melhor ou mais adequado para se construir marcas de sucesso. Ao contrário, como ressalta Calkins (2006, p. 3-4), parece muito simples apresentar um bom nome, um logo atraente e um slogan interessante; no entanto, a realidade é que criar e desenvolver marcas são os dois maiores desafios enfrentados pelos gerentes, sendo um trabalho que pode levar anos até obter bons frutos. Em seus estudos, Calkins (2006, p. 4-8) enfatiza que os principais desafios na construção de marcas estão atrelados a restrições financeiras que limitam investimentos, à conscientização entre os membros da organização quanto aos princípios e valores das marcas, bem como à saturação de mercado e à concorrência hoje elevadíssima.

Calkins (2006, p. 7), entretanto, ressalta a importância do posicionamento de uma marca, já que marcas fracas e com posicionamento duvidoso são desinteressantes e não significam muita coisa. Como exemplo de marcas com posicionamento claro, ele cita o Walmart, que é conhecido por preços baixos, e a Tiffany, que é sinônimo de luxo e exclusividade. Esse autor enfatiza que as marcas precisam ser criativas para atrair a atenção; propaganda se faz necessário, mas é preciso investir em outros recursos de comunicação e pontos de contato, identificando e executando ideias únicas, criativas e que sejam capazes de atrair a atenção dos consumidores.

Para Alice M. Tybout e Brian Sternthal (2006, p. 11-12), o posicionamento de marca deve incluir as metas que o cliente espera atingir ao usar a marca e por que, em um mercado saturado, ela é superior ou deve ser escolhida por parte do consumidor. Esse ponto de diferença pode ser baseado em benefícios funcionais (como a argumentação da marca Gillete, de que suas lâminas proporcionam um barbear mais rente e confortável), bem como em benefícios emocionais (como 0 conceito de que comer no McDonald's é divertido). Como enfatiza Semprini (2010, p.4 8), há tempos os consumidores pararam de se apaixonar por novidades, pois estão dispostos a aderir a novas propostas caso percebam a possibilidade de a oferta thes atribuir sentido ou valor superior.

Daniela M. R Khauaja (2008, p. 94-96) explica que, embora uma comunidade possa ser formada em torno de qualquer marca, é mais provável que ela se forme em torno de marcas que possuam uma imagem sólida, um histórico de relacionamento com seus clientes e até uma forte concorrência, pois isso eleva a probabilidade de os consumidores fiéis as defenderem. Esses 
mesmos consumidores também exigem de suas marcas uma postura ética, o que reforça a importância do compromisso com a responsabilidade social e a boa governança para impulsionar o valor das marcas. Tais afirmações vão ao encontro de Kotler, Kartajaya e Setiawan (2010, p.16), quando eles afirmam que "as pessoas anseiam por marcas responsáveis que sejam responsivas aos consumidores e se esforcem para fazer do mundo um lugar melhor".

O Instituto Akatu (2013, p. 86-87) revela que atitudes de sustentabilidade e de responsabilidade social já não são mais vistos como diferenciais de marcas e sim como obrigações das empresas; muitos consumidores exigem de suas marcas uma posição social e ambiental, e não basta "pegar carona" na onda do investimento social ou ambiental apenas pelo propósito de valorizar uma marca, pois, afinal, não se pode achar que os consumidores são desinformados a ponto de se fidelizarem por exposições midiáticas oportunistas. Além disso, se os cuidados com o meio ambiente e outras abordagens do contato social com a marca já são considerados obrigatórios no ponto de vista de muitos consumidores, pode-se então abrir espaço para o olhar em ações ou projetos mais pontuais e com foco em grupos específicos de consumidores, sobretudo aqueles que compõem o mercado principal de cada marca.

\section{CAUSAS, PATROCÍNIO E LEIS DE INCENTIVO}

Kotler e Keller (2006, p. 712) explicam que a responsabilidade corporativa de uma empresa se compõe do comportamento apropriado nos âmbitos legais, éticos e de responsabilidade social. Para esses autores, as pessoas estão cada vez mais informadas sobre o histórico das empresas quanto à sua responsabilidade social e ambiental, para decidir de quais comprar, em quais investir e para quais trabalhar.

Yanaze (2011, p. 617) argumenta que marketing relacionado a causas é o termo mais adequado para se referir a projetos que associam empresas e marcas a uma questão ou causa social relevante, com benefício para a sociedade ou para ela mesma. Tal investimento "usa o poder da marca e do marketing nas necessidades da causa e da comunidade, para se alcançar um benefício mútuo".

Tanto a marca como as entidades beneficiadas, nesse tipo de investimento, lucram. Por um lado, ganha a marca pela capitalização de imagem e também por maior incremento de vendas; por outro, ganham as entidades pela arrecadação de recursos financeiros. Kotler, Hessekiel e Lee (2012, p. 6) mencionam que os indícios das últimas décadas apontam aumento no patrocínio de causas sociais, além de mudanças de atitudes em relação às contribuições, que já deixaram de ser vistas por muitas empresas como obrigações e passaram a ser encaradas como estratégias de mercado.

Várias causas sociais podem se encaixar no escopo das estratégias de investimento por parte das organizações, sejam temas populares ou pouco difundidos. Citem-se, por exemplo, o combate à pobreza e à fome, o apoio ao tratamento de doenças como 0 câncer e diabetes, o suporte a deficientes, 0 apoio a iniciativas socioculturais em comunidades de baixa renda etc. Nas palavras de Kotler, Hessekiel e Lee (2012, p. 5),

as causas apoiadas com mais frequência por essas iniciativas são as que contribuem para a saúde (prevenção da aids, deteç̧ão precoce do câncer de mama, imunizações oportunas); segurança (educação no trânsito, prevenção de crimes, direção segura); educação(alfabetização, computadores para escolas, educação de portadores de necessidades especiais); emprego (treinamento no emprego, práticas de contratação de pessoal, localização de fábricas); meio ambiente (reciclagem, eliminação do uso de produtos químicos tóxicos, redução das embalagens); desenvolvimento comunitário e econômico (financiamentos imobiliários com juros baixos); outras necessidades e expectativas humanas básicas (alimentação, habitação, proteção dos direitos dos animais, exercício de privilégios de voto, antidiscriminação). 
A Cone Communications e a Echo (2013, p. 34-35), a partir de um levantamento com 10 mil indivíduos no Canadá, Brasil, Estados Unidos, Reino Unido, Alemanha, França, Rússia, China, Índia e Japão, revela que mais de 62\% dos usuários de redes sociais utilizam esses canais para se envolver com as organizações, sendo que $34 \%$ compartilham informações positivas sobre essas organizações e suas atividades, $29 \%$ usam redes sociais para aprender mais sobre organizações especificas e suas atividades e $26 \%$ usam as mesmas redes sociais para compartilhar informações negativas sobre as empresas. Outro dado interessante (Cone; Echo, 2013, p. 8) é que apenas 6\% dos consumidores acreditam que as empresas existem apenas para ganhar dinheiro e somente $13 \%$ dizem que elas podem exercer papel limitado na sociedade. Para $21 \%$, as empresas devem apoiar questões sociais ou ambientais doando produtos ou serviços, dinheiro ou voluntários; para 29\% elas devem não apenas apoiar questões sociais, mas também defender as questões sociais e ambientais, aumentando a conscientização e doação de produtos, serviços, dinheiro e voluntários; e para a maioria dos entrevistados (31\%), as empresas devem mudar a maneira como operam e se alinhar com as necessidades sociais e ambientais dos lugares em que operam.

Kotler, Hessekiel e Lee (2012, p. 8-10), em concordância, afirmam que as empresas devem deixar a abordagem tradicional ou antiga, que entende o investimento em causas sociais como obrigação, para progredirem com uma nova abordagem, que incorpora esses investimentos sociais ao próprio objetivo da empresa.

Rudimar Baldissera (2011, p. 184-185) explica que, em resposta à pressão exercida pela sociedade, algumas organizações assumem atitudes que parecem mais responsáveis, enquanto outras, poucas, realmente estão realizando importantes esforços para que a ideia de responsabilidade social empresarial seja parte da filosofia e dos pressupostos básicos da organização. Esse autor destaca o termo "parece", porque considera que boa parte das ações de responsabilidade social não passa de mera ação para atender à legislação vigente ou é algum tipo de compensação por danos causados pela organização, seja no âmbito social, ecológico, cultural ou econômico.

Em suas argumentações, Baldissera (2011) não quer dizer que as organizações não podem ou não devem divulgar suas ações ou seus projetos de responsabilidade social. A questão está no uso leviano de um discurso oportunista, em nome da responsabilidade social, apenas buscando a repercussão midiática para obter autopromoção e sobressair com valores positivos perante outros. Como 0 autor reitera (Baldissera, 2011, p. 185), a essência da responsabilidade social é o contrário desse caráter oportunista, projetado apenas com a intenção de usar comunicação e marketing para autopromoção.

O processo parece ainda lento, derivado das transformações do marketing, mas algumas organizações já compreendem que criar simpatia por suas marcas não se faz somente com patrocínios de alto impacto midiático, como a utilização recorrente de programas de auxílio a amputados, doentes oncológicos, com mal de Alzheimer etc., a partir de uma mazela de ações comunicacionais oportunistas e rasas. 0 patrocínio oportuno, e não oportunista, ligado muitas vezes ao core business da organização, produz maior sensação de pertinência e verdade. Já há mesmo organizações que realizam o patrocínio e sequer divulgam essa ação na mídia.

Há, portanto, uma grande diferença entre organizações que incorporam a responsabilidade social no âmago de suas bases e aquelas que apenas a colocam dentro do marketing e da comunicação com intenções meramente oportunistas, mercadológicas e de autopromoção, com base em exposições midiáticas e massivas.

Kotler e Keller (2006, p. 592) argumentam que os profissionais de marketing estão se tornando mais estratégicos em relação àqueles que pretendem se envolver ou patrocinar e à maneira pelo qual o farão, mas alertam que o público atingido nesse tipo de ação deve corresponder ao mercado-alvo almejado pela marca. 
O governo brasileiro possui leis que incentivam empresas e pessoas físicas a investirem ou patrocinarem ações em prol da cultura, educação, pesquisa, esporte, saúde ou ações sociais. A Lei Rouanet (de 1991, sucessora da Lei Sarney), aprova projetos de natureza cultural, enquanto os fundos nacional, estaduais e municipais dos Direitos da Criança e do Adolescente contam com projetos que apoiam o crescimento ou o desenvolvimento da criança e do adolescente. A Lei do Audiovisual (de 1993), incentiva a produção e a difusão de obras audiovisuais cinematográficas brasileiras e a Lei de Incentivo ao Esporte (de 1996) aprova projetos relacionados à prática esportiva e paradesportiva. A partir da criação da Lei de Incentivo à Pesquisa (em 2005), as empresas podem investir em projetos de pesquisa e inovação tecnológica. Já o Fundo Nacional do Idoso (de 2010 e que inclui fundos estaduais e municipais) sustenta projetos que se preocupam com a qualidade de vida de idosos com 60 anos ou mais. Os Programa Nacional de Apoio à Atenção Oncológica (Pronon) e o Programa Nacional de Apoio à Atenção da Saúde da Pessoa com Deficiência (Pronas/PCD), de 2013, relacionam-se com o combate ao câncer e o apoio a deficientes. Ao apoiar projetos por essas leis, as organizações ou pessoas físicas podem resgatar o valor investido (observando-se os limites) na próxima cobrança do imposto de renda.

Com essas leis, as organizações possuem várias opções para investimento, podendo, em muitos casos, optar por temas mais ligados ao seu negócio. No entanto, investir em uma causa mais conhecida parece ser a escolha da maioria das organizações, talvez porque isso possibilite uma divulgação mais expressiva na mídia. Contudo, existem outras causas alternativas que, mesmo representando um enorme contingente de pessoas, pouco são apoiadas ou patrocinadas pelas empresas. Para demonstrar essa contradição entre uma causa de maior impacto e outra causa menos conhecida, pode-se avaliar o investimento em cegos e institutos ligados a deficientes visuais, em contraste com o investimento em daltônicos.

Para se ter uma noção, Lindsay T. Sharpe e outros (1991, p. 26) explicam que a incidência de daltônicos varia entre humanos de diferentes origens raciais; no entanto eles revelam que cerca de $8 \%$ dos homens possuem algum tipo de daltonismo, sendo o percentual para mulheres de cerca de 0,5\% (a amostragem desse estudo foi, em maioria, de descendentes europeus). Embora existam divergências entre sites, artigos e livros que abordam o daltonismo ${ }^{3}$, a maioria considera que a média de daltônicos fica em torno de $5 \%$ a $8 \%$ da população mundial, havendo variação em diferentes regiões do mundo. Isso é suficiente para observar que o número de daltônicos pode ser de cinco a oito vezes mais do que o de indivíduos com cegueira (que não representam nem $1 \%$ do universo global) ${ }^{4}$. No entanto, 0 apoio a cegos por parte de marcas parece muito maior do que 0 apoio a daltônicos. Para verificar tal constatação, uma pesquisa foi aplicada a duas empresas com um histórico de investimentos em causas sociais, questionando-as sobre a possibilidade de investimento em causas alternativas, tendo como exemplo o próprio daltonismo.

\section{ANÁLISE DE PESQUISA APLICADA - GRUPO ABRIL E VOLKSWAGEN DO BRASIL}

A metodologia para a pesquisa aplicada se estabeleceu a partir de uma entrevista em profundidade, por meio de amostra não-probabilística intencional, com definição prévia dos seguintes itens de roteiro:

- Importância das estratégias em prol das causas sociais.

- Causas sociais com as quais a organização está envolvida.

3 Para citar alguns, no livro A psicologia das cores, Eva Heller (2013, p. 273) escreve que cerca de 5\% da população global é daltônica, sendo 4\% homens. Já em 0 guia completo da cor, Tom Fraser e Adam Banks (2007, p. 28) falam em torno de 8\% dos homens e 0,5\% de mulheres. Em psicodinâmica das cores em comunicação, Modesto Farina, Clotilde Perez e Dorinho Bastos (2011, p. 55) argumentam que 10\% da população mundial é daltônica, da qual 95\% são homens.

4 Avaliação da Secretaria de Direitos Humanos da Presidência da República (2012), com base no Censo 2010. 
- Benefícios e dificuldades no investimento em causas sociais.

- Retorno para a organização (valorização de marcas).

- Uso de leis de incentivo para patrocinar causas sociais.

- Divulgação de ações em prol de causas sociais.

- Conhecimento sobre o daltonismo.

- Adaptações para daltônicos dentro da organização.

- Conhecimento sobre ações que beneficiam os daltônicos.

- Daltônicos como estratégia de causa social.

Como já mencionado, a justificativa para a escolha do daltonismo como exemplo de uma causa menos difundida é que, embora se trate de uma deficiência da visão cromática em muitos indivíduos (sobretudo homens), não é um tema tão difundido ou bem compreendido por grande parte da sociedade ou até por muitos profissionais que trabalham com a cor. 0 daltonismo parece receber pouco apoio por parte de marcas organizacionais, incluindo aquelas cujo principal segmento de atuação está ligado à codificação de mensagens coloridas ou à fabricação de produtos que envolvem a cor.

\section{Grupo Abril}

A entrevista com o gerente de Comunicação e o gerente de Sustentabilidade do Grupo Abril demonstra que a organização reconhece a importância de investir em sustentabilidade e apoiar causas sociais, sobretudo temas relacionados a educação.

Quando os respondentes revelam que o Grupo Abril oferece anúncios bonificados a entidades sem fins lucrativos, e que é estratégia da organização oferecer menos apoio financeiro e mais apoio efetivo de mídia (doação de anúncios bonificados), isso corrobora que o apoio às causas sociais faz parte da cultura do Grupo Abril, além de mostrar que não há a pretensão, nos anúncios bonificados, de fazer autopromoção às custas das iniciativas de terceiros. Embora esses anúncios carreguem o selo "Abril apoia esta causa", os anúncios bonificados são oferecidos de forma transparente, e em caráter de doação, com a intenção de ajudar entidades a dar visibilidade aos projetos. Considerando que são elegíveis para os anúncios instituições que não possuem fins lucrativos e que tenham projetos sociais de qualquer âmbito, pode-se entender com isso que 0 daltonismo e outros temas menos difundidos poderiam ter espaço dentro do escopo de apoio do Grupo Abril.

Não houve surpresas quando os respondentes do Grupo Abril alegaram ter pouquíssimo conhecimento quanto ao daltonismo ou ao universo de pessoas que eles representam. No entanto, ao serem questionados se visualizam a possibilidade de produzir revistas ou outros materiais adaptados a daltônicos, dizem que não sabem no momento se esta é uma possibilidade passível de execução. Parece, entretanto, haver uma dicotomia entre apoio social e retornos financeiros quando eles argumentam que acham difícil imaginar o investimento em materiais adaptados especificamente a daltônicos, mesmo considerando que estes podem representar um universo entre $5 \%$ a $8 \%$ de brasileiros, isto é, cerca de 10 a 18 milhões de pessoas. De fato, 20 milhões de pessoas podem não ser uma representação estatística considerável; no entanto, representam sim um enorme número de brasileiros que são partícipes de uma sociedade que se diz inclusiva. Ao que isto indica, mais ou menos 15 ou 20 milhões de brasileiros não parecem um universo ainda relevante; tal parecer é reiterado quando um dos respondentes argumenta que, no momento, o Grupo Abril investe dinheiro no que tem certeza que vai dar um retorno e não no que seria incerteza para cerca de $10 \%$ do universo de brasileiros. 
Já o investimento em sites e materiais digitais, que refletem menos investimentos financeiros se comparados ao de materiais impressos adaptados, é considerado pelos respondentes como potencial e com crescentes possibilidades para 0 apoio ao universo de daltônicos, bem como outras causas sociais diversas.

Nota-se, a partir das argumentações, que os daltônicos e até outros temas menos difundidos podem receber apoio por parte do Grupo Abril, seja em anúncios bonificados, em projetos baseados em leis de incentivo ou em pautas de diferentes revistas que elevam a conscientização social acerca do tema (é claro que é preciso levar em consideração que os órgãos ligados ao daltonismo devem se preocupar em gerar produtos que possam ser "vendáveis", isto é, que possam se concretizar em produtos ou campanhas para mais suporte, acessibilidade ou conscientização do público).

No entanto, quando se pensa em qualquer tipo de esforço que leve a organização a investir dinheiro, começam os diversos cálculos para mensurar como isso pode gerar retorno para a organização. As oportunidades, portanto, se direcionam a temas que atingem um universo maior de indivíduos ou que são mais conhecidos na sociedade.

\section{Volkswagen do Brasil}

Com relação à entrevista com o gerente de Assuntos Corporativos da Volkswagen do Brasil, ele enfatiza a importância do investimento em causas sociais e da responsabilidade ética e social para sua organização. A Volkswagen apoia projetos baseados em leis de incentivo e ações concentradas em regiões próximas às suas fábricas. Outro ponto positivo é que a organização criou um comitê que envolve as áreas de marketing, comunicação, recursos humanos, jurídica, financeira, governamentais e até a Fundação Volkswagen, para que todas caminhem em sincronia e juntas tomem decisões colegiadas sobre projetos nos quais investir ou os quais patrocinar.

Mais um ponto a ser destacado é que nem todas as ações praticadas pela Volkswagen são expostas na mídia. Além disso, temas menos conhecidos ou causas mais pontuais e referentes a uma comunidade específica também podem ter espaço para receber apoio da Volkswagen do Brasil: na entrevista foram citadas uma ação que oferece suporte a crianças carentes em uma comunidade em frente a uma das fábricas da organização, bem como um projeto de formação musical em uma favela da cidade de São Paulo. A Volkswagen, segundo o respondente, patrocina anualmente cerca de 15 projetos de cunho social, sendo nítida a estratégia da organização em concentrar o investimento nas comunidades onde ela tenha fábricas instaladas.

Outro trecho da entrevista que corrobora esse ponto de vista encontra-se no quinto item do roteiro (uso de leis de incentivo), quando o respondente reitera que a Volkswagen investe em projetos com perfil sociocultural, não importando o retorno de mídia, mas sim a iniciativa da empresa em ajudar as pessoas de alguma forma.

Quando, entretanto, a entrevista questiona o respondente sobre seu conhecimento acerca do tema "daltonismo", ele revela, assim como os executivos do Grupo Abril, pouquíssimo conhecimento. 0 respondente informa que nunca recebeu qualquer proposta de apoiar um projeto (com base em leis de incentivo) que tenha foco no apoio aos daltônicos, mas também considera pouco favorável o apoio a esse grupo de indivíduos, pois, na opinião dele, o daltonismo não é um tema que "choca as pessoas" por não apresentar alterações físicas ou comportamentais.

Essa opinião também é evidente quando ele menciona que é comum ajudar crianças com câncer ou mesmo o esporte paralímpico, porque é mais fácil o público se sensibilizar com uma pessoa sem um membro ou com alguma outra dificuldade. 
O que se evidencia, a partir dessas argumentações, é que o apoio a amputados ou indivíduos com doenças degenerativas, crianças desnutridas ou esforços contra atos de violência e guerras são temas preeminentes para investimento, porrque sensibilizam muito mais o público do que outros temas menos conhecidos ou que geram menos repercussão midiática, como o daltonismo, a compulsão sexual ou certas doenças raras como a anemia falciforme.

\section{CONSIDERAÇÕES FINAIS}

Há organizações que já entendem seu papel social e não precisam expor massivamente suas ações na mídia ou projetar sua política de investimentos em temas de grande repercussão, como o câncer, a desnutrição e a pobreza, apenas para mostrar aos consumidores que estão preocupadas com a sociedade. Já existem empresas que patrocinam certas causas sociais (ou ofereceram doações a entidades necessitadas), mas nem sequer informam tal fato na mídia: o Grupo Abril e a Volkswagen do Brasil declararam que praticam esse tipo de doação.

Como reforça Baldissera (2011, p. 184-185), muitas empresas se apoiam no contexto social apenas para atender à legislação ou para compensar os danos que a organização causa à sociedade em termos sociais, ecológicos, culturais ou econômicos. Para esse autor, há grande diferença entre organizações que assumem atitudes responsáveis e as que se apoiam em ações sociais (ou na sustentabilidade) como estratégias de marketing com fins de autopromoção e visibilidade.

Em nenhum momento houve a expectativa de avaliar quebras de paradigma ou comparar se investimentos em causas sociais mais populares ou conhecidas, bem como causas que possuem expressivos gastos com divulgação na mídia, são mais efetivos, melhores ou piores do que investimentos em causas sociais alternativas, que se valem da mídia espontânea ou de divulgação reservada. Mas o que se pôde verificar por meio da pesquisa é que parece haver uma certa transformação no modo como várias empresas entendem o investimento em causas sociais.

Como há um crescente número de consumidores que entendem como obrigação (e não diferencial) a responsabilidade social e ambiental por parte das organizações, estas podem seguir duas vertentes para atender os anseios do público.

Em primeiro lugar, podem considerar o investimento em causas sociais e o controle dos aspectos de sustentabilidade como obrigação ou estratégias de marketing com finalidade de autopromoção (Baldissera, 2011, p. 184-185), apoiando-se, neste caso, sobretudo na publicidade e nas articulações das relações públicas para sensibilizar os indivíduos e demonstrar 0 quanto fazem o bem para a sociedade. Já uma segunda forma de pensar, embora também se reconheça a necessidade de cuidar de cada etapa de produção, evitar o desperdício de recursos naturais e investir na sociedade, entende que essas não são apenas obrigações (ou estratégias de marketing para ganhar visibilidade), mas características que devem ser incorporadas à cultura da empresa, desde seus inputs até seus outputs. Kotler, Hessekiel e Lee (2012, p. 8-10) aconselham as empresas a agirem dessa forma, deixando a abordagem tradicional que entende o investimento em causas sociais como obrigação para progredir com a nova abordagem que incorpora tais princípios no objetivo da empresa.

Em muitos relatos das entrevistas aplicadas ao Grupo Abril eà Volkswagen do Brasilé possível avaliar que essas organizações consideram o investimento social e a sustentabilidade como parte de sua cultura, havendo espaço para abrirem um pouco mais o leque de possibilidades e apoiarem causas mais pontuais ou menos exploradas. 
De qualquer forma, quando um tema pouco difundido ou esclarecido é abordado - como o daltonismo -, tanto os executivos do Grupo Abril como o da Volkswagen do Brasil sentem um certo desconforto em se pronunciar a respeito. Eles iniciam uma análise, de certa forma dicotômica, sobre quais as vantagens de se investir no universo de daltônicos e com isso obter retorno de imagem para a organização.

Apenas para se ter uma ideia, o IBGE indicava, há seis anos (Sinopse, 2010) que a população brasileira era de cerca de 190 milhões de indivíduos. A partir de um cálculo simples, podia-se prever que a média de $5 \%$ a $8 \%$ de daltônicos equivalia a um universo que pode alcançar até 15 milhões de pessoas. Esta quantidade podia até não ser uma representação estatística considerável, mas não havia como negar que representava um enorme número de brasileiros partícipes de uma sociedade que se diz inclusiva.

Embora, como já argumentado, existam organizações que deixaram de considerar o investimento em causas sociais como obrigação, apenas para atender uma demanda de consumidores mais informados e exigentes, a avaliação de temas como 0 daltonismo, que mostram uma dicotomia entre investir, mas ter a certeza de obter retornos, ajudam a perceber um estágio de mudança ainda em amadurecimento.

Não se escolheu o daltonismo, na pesquisa, porque se pretendia avaliar por que tal assunto é pouco conhecido, como ele pode se tornar mais popular ou tampouco mostrar que nenhuma organização de qualquer âmbito se importa com a respectiva causa. Na verdade, o que se tinha em vista era mostrar que ainda há mais a se avançar quando o assunto é o investimento em causas sociais, pois muitas vezes as organizações optam por causas mais conhecidas ou que geram mais exposição (por exemplo, cegos, amputados, fome, crimes, tráfico, pobreza) do que em causas que poucos conhecem ou que são uma incerteza quanto a consideráveis retornos de imagem.

De maneira geral, causas sociais alternativas como o daltonismo talvez se tornem mais propensas a receber investimento por parte das organizações - sobretudo aquelas que possuem na cor todo ou parte do seu negócio principal -caso se tornem temas mais populares ou difundidos na mídia. Mesmo tendo-se a ideia de um universo que pode alcançar até 15 milhões de brasileiros, e mesmo considerando esse público como um nicho a que poucas marcas estão associadas, a incerteza de se investir e obter poucos retornos de imagem (principalmente se não houver leis de incentivo por trás dos projetos) torna-se uma barreira para muitas organizações, que preferem então optar por outras causas mais conhecidas e com mais certeza de retorno. Parece uma mentalidade ainda resistente dentro de sociedades supostamente inclusivas.

\section{REFERÊNCIAS}

BALDISSERA, Rudimar. Da responsabilidade social à sustentabilidade: comunicação, cultura e imaginários. In: FARIAS, Luiz A. (org.). Relações públicas estratégicas: técnicas, conceitos e instrumentos. São Paulo: Summus, 2011.

CALDER, Bobby J. Design de marcas. In: TYBOUT, Alice M.; CALKINS, Tim (orgs.). Branding: fundamentos, estratégias e alavancagem de marcas. São Paulo: Atlas, 2006.

CALKINS, Tim. Introdução: o desafio de branding. In: TYBOUT, Alice M.; CALKINS, Tim (orgs.). Branding: fundamentos, estratégias e alavancagem de marcas. São Paulo: Atlas, 2006.

CONE COMMUNICATIONS; ECHO. 2013 Cone communications/Echo global study. [s. l.]: Cone, 2003. Disponível em: <http:// www.conecomm.com/2013-global-csr-study-release>. Acesso em: 21 ago. 2015. 
DI FELICE, Massimo. Das tecnologias da democracia para as tecnologias da colaboração. In: DI FELICE, Massimo (org.). Do público para as redes. São Caetano do Sul (SP): Difusão, 2008.

FARINA, Modesto; PEREZ, Clotilde; BASTOS, Dorinho; Psicodinâmica das cores em comunicação. 6. ed. São Paulo: Edgard Blücher, 2011.

FRASER, Tom; BANKS, Adam. O guia completo da cor. São Paulo: Editora Senac São Paulo, 2007.

HELLER, Eva. A psicologia das cores: como as cores afetam a emoção e a razão. São Paulo: Gustavo Gili, 2013.

INSTITUTO AKATU. Pesquisa Akatu 2012: rumo à sociedade do bem-estar. São Paulo: Instituto Akatu 2013. Disponível em: <http://www.akatu.org.br/pesquisa/2012/ PESQUISAAKATU.pdf>. Acesso em: 6 ago. 2015.

KHAUAJA, Daniela M. R.; Construção de marcas. In: SERRALVO, Francisco A. Gestão de marcas no contexto brasileiro. São Paulo: Saraiva, 2008.

KOTLER, Philip; HESSEKIEL, David; LEE, Nancy. Boas ações: uma nova abordagem empresarial. Rio de Janeiro: Elsevier, 2012.

KOTLER, Philip; KARTAJAYA, Hermawan; SETIAWAN, Iwan. Marketing 3.0: as forças que estão definindo o novo marketing centrado no ser humano. Rio de Janeiro: Elsevier, 2010.

KOTLER, Philip; KELLER, Kevin L. Administração de marketing. 12. ed. São Paulo: Prentice Hall, 2006.

Administração de marketing. 14. ed. São Paulo: Prentice Hall, 2012.

NORDSTROM, Kjell; RIDDERSTRALE, Jonas. Funky business: talento movimenta capitais. São Paulo: Makron Books, 2001.

SECRETARIA DE DIREITOS HUMANOS DA PRESIDÊNCIA DA REPÚBLICA. Cartilha do Censo 2010 - Pessoas com Deficiência. Brasília:SDH-PR/SNPD, 2012. Disponível em:<http://www.pessoacomdeficiencia.gov.br/app/sites/default/files/publicacoes/ cartilha-censo-2010-pessoas-com-deficienciareduzido.pdf>. Acesso em: 12 jun. 2015.

SEMPRINI, Andrea. A marca pós-moderna: poder e fragilidade da Marca na sociedade contemporânea. 2. ed. São Paulo: Estação das Letras e Cores, 2010.

SHARPE, Lindsay T. et al. Opsin genes, cone photopigments, color vision, and color blindness. In: GEGENFURTNER, Karl R; SHARPE, Lindsay T. Color vision: from genes to perception. Cambridge University Press: New York, 1999. p. 3-51. Disponível em: <http://www.allpsych.uni-giessen.de/karl/colbook/sharpe.pdf>. Acesso em: 18 jun. 2015.

SINOPSE do Censo Demográfico 2010 - População. IBGE. Brasília, 2010. Disponível em: <http://www.censo2010.ibge.gov.br/ sinopse/index.php?dados=8>. Acesso em: 9 set. 2015.

TOFFLER, Alvin. A terceira onda. 32. ed. Rio de Janeiro: Record, 2014.

TYBOUT, Alice M.; STERNTHAL, Brian. Posicionamento de marca. In: TYBOUT, Alice M.; CALKINS, Tim (orgs.). Branding: fundamentos, estratégias e alavancagem de marcas. São Paulo: Atlas, 2006.

YANAZE, Mitsuru H. Gestão de marketing e comunicação: avanços e aplicações. 2. ed. São Paulo: Saraiva, 2011.

Artigo recebido em 02.02.2016 e aprovado em 25.06.2016. 